\title{
Effect of inhaled bronchodilators on inspiratory capacity and dyspnoea at rest in COPD
}

\author{
F. Di Marco*, J. Milic-Emili", B. Boveri*, P. Carlucci", P. Santus*, F. Casanova*, M. Cazzola ${ }^{+}$, \\ S. Centanni*
}

Effect of inhaled bronchodilators on inspiratory capacity and dyspnoea at rest in COPD. F. Di Marco, J. Milic-Emili, B. Boveri, P. Carlucci, P. Santus, F. Casanova, M. Cazzola, S. Centanni. (C) ERS Journals Ltd 2003.

ABSTRACT: It has been shown that patients with chronic obstructive pulmonary disease (COPD) develop dynamic hyperinflation (DH), which contributes to dyspnoea and exercise intolerance. Formoterol, salmeterol and oxitropium have been recommended for maintenance therapy in COPD patients, but their effect on DH has only been assessed for salmeterol.

The aim of the present study was to compare the acute effect of four inhaled bronchodilators (salbutamol, formoterol, salmeterol and oxitropium) and placebo on forced expiratory volume in one second, inspiratory capacity, forced vital capacity and dyspnoea in COPD patients. A cross-over, randomised, double-blind, placebocontrolled study was carried out on 20 COPD patients.

Patients underwent pulmonary function testing and dyspnoea evaluation, in basal condition and 5, 15, 30, 60 and $120 \mathrm{~min}$ after bronchodilator or placebo administration.

The results indicate that in chronic obstructive pulmonary disease patients with decreased baseline inspiratory capacity, there was a much greater increase of inspiratory capacity after bronchodilator administration, which correlated closely with the improvement of dyspnoea sensation at rest. For all bronchodilators used, inspiratory capacity reversibility should be tested at 30 min following the bronchodilator. On average, formoterol elicited the greatest increase in inspiratory capacity than the other bronchodilators used, though the difference was significant only with salmeterol and oxitropium. The potential advantage of formoterol needs to be tested in a larger patient population.

Eur Respir J 2003; 21: 86-94.

\begin{abstract}
*University of Milan, San Paolo Hospital, Respiratory Unit, Milan, Italy \#Meakins-Cristie Laboratories, McGill University, Montreal, Quebec, Canada. Institute of Respiratory Diseases, University of Milan IRCCS, Ospedale Maggiore, Milan, Italy. ${ }^{+}$Division of Pneumology and Allergology and Unit of Respiratory Clinical Pharmacology, A. Cardarelli Hospital, Naples, Italy.
\end{abstract}

Correspondence: S. Centanni, San Paolo Hospital, 20142 Milan, Italy. Fax: 390289123960

E-mail: stefano.centanni@unimi.it

Keywords: Dynamic hyperinflation expiratory flow limitation

formoterol

oxitropium

salbutamol

salmeterol

Received: March 122002

Accepted after revision: August 222002
In patients with chronic obstructive pulmonary disease (COPD), bronchodilator reversibility testing is used routinely to exclude a significant asthmatic component. International guidelines recommend that bronchodilator responsiveness be evaluated by the change in forced expiratory volume in one second (FEV1) greater than a cut-off level, calculated in different ways [1, 2]. However, in COPD patients, exercise tolerance and dyspnoea are poorly correlated with FEV1 [3-5]. Recently, it has been shown that in COPD patients, indices related to dynamic hyperinflation (DH), such as inspiratory capacity (IC), are both reproducible [6] and more closely related to exercise tolerance and dyspnoea than FEV1 and forced vital capacity (FVC) [3, 6-11]. Pellegrino et al. [11] demonstrated that changes in FEV1 frequently fail to detect significant functional responses to bronchodilators in patients with chronic airflow obstruction. Furthermore, an increase in IC after bronchodilator administration implies a reduction in $\mathrm{DH}$, which is the main cause of reduced exercise capacity and dyspnoea [7-12]. Accordingly, an increase in IC should represent the main target for bronchodilator therapy.
The effect of bronchodilator administration on IC and other ventilatory variables in COPD patients has been described in several publications [8, 10, 13-18]. However, bronchodilator-induced changes in IC were correlated with the concurrent changes in dyspnoea sensation in COPD patients at rest in only one study [14]. Surprisingly, the changes in IC $(\Delta I C)$ correlated poorly with those in dyspnoea. In contrast, the latter correlated well with the forced inspiratory volume in one second. However, the poor correlation between $\Delta \mathrm{IC}$ and improvement of dyspnoea is probably due to the fact that patients were not separated into those with and without baseline $\mathrm{DH}$; only the latter exhibits a significant reduction of $\mathrm{DH}$ after bronchodilator administration, reflected by decreased functional residual capacity (FRC) and increased IC [19].

The purpose of the present study was to evaluate the acute effect of four inhaled bronchodilators (salbutamol, formoterol, salmeterol and oxitropium) and placebo on IC, FEV1, FVC, FEV1/FVC and dyspnoea at rest in COPD patients, and to assess the correlation between the changes in these variables. The patients were separated into two groups, those with normal and those with reduced IC $(<80 \%$ 
predicted), because the effect of bronchodilators on IC should be more pronounced in the latter group [19]. Long-acting bronchodilators were included because present international guidelines on COPD management [20] suggest treatment with long-acting bronchodilators, such as long-acting $\beta_{2}$-agonists (formoterol and salmeterol) or anticholinergic drugs (oxitropium).

\section{Methods}

\section{Subjects}

Twenty consecutive COPD outpatients (14 males) were enrolled. Inclusion criteria were: $>35$ yrs of age, current or former smoker $(>10$ pack-yrs) and a diagnosis of COPD as defined by the American Thoracic Society (ATS) [21], an FEV1/FVC ratio of $<70 \%$, and a baseline severity of breathlessness of at least grade 1 (short of breath when hurrying on a level or walking up a slight hill) according to the modified Medical Research Council (MRC) dyspnoea scale [22]. Exclusion criteria included: unstable respiratory status within the previous 4 weeks, a known history of asthma or chronic respiratory disease other than COPD, any clinically significant concurrent disease, and a change in medication for COPD within the 4 weeks prior to the screening visit. Patients' anthropometric characteristics and lung function data are given in table 1. Each patient gave informed consent and the study protocol was approved by the local ethics committee.

\section{Study design}

A cross-over, randomised, double-blind, placebocontrolled study was carried out on 20 consecutive patients with stable COPD. On 5 separate days (within a span of no more than 10 days between the first and the last study day), patients underwent pulmonary function testing and dyspnoea evaluation, under basal conditions and after bronchodilator administration. Standard drug dosage, as suggested by international guidelines for COPD management [20], was used: two salbutamol inhalations $(200 \mu \mathrm{g})$; one formoterol fumarate inhalation $(12 \mu \mathrm{g})$ plus one placebo inhalation; two salmeterol xinafoate inhalations $(50 \mu \mathrm{g})$; two oxitropium bromide inhalations $(200 \mu \mathrm{g})$; and two placebo inhalations.

The drugs were administered randomly. In addition, the placebo study was performed simultaneously with formoterol in all patients. Drugs were administered by metered-dose inhaler using a blind holding

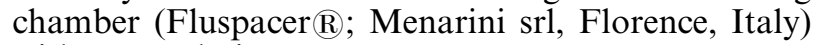
with a mouthpiece.

\section{Methods}

In the basal condition and 5, 15, 30, 60 and $120 \mathrm{~min}$ after bronchodilator administration, FEV1, IC, FVC and dyspnoea were assessed. The patients were investigated in the morning in a sitting position. None had received inhaled short-acting $\beta_{2}$-agonists for $8 \mathrm{~h}$, or long-acting $\beta_{2}$-agonists or oxitropium bromide for $24 \mathrm{~h}$, before the study. None of the patients were receiving oral $\beta_{2}$-agonists, theophylline or systemic corticosteroids. Spirometric measurements

Table 1. - Anthropometric characteristics and baseline respiratory data of chronic obstructive pulmonary disease patients

\begin{tabular}{|c|c|c|c|c|}
\hline & All patients & $\begin{array}{l}\text { Patients with } \\
\text { basal IC }<80 \% \\
\text { pred }\end{array}$ & $\begin{array}{l}\text { Patients with } \\
\text { basal IC }>80 \% \\
\text { pred }\end{array}$ & $\mathrm{p}$-value \\
\hline Patients $\mathrm{n}$ & 20 & 12 & 8 & \\
\hline Sex M/F & $14 / 6$ & $9 / 3$ & $5 / 3$ & 0.92 \\
\hline IC $\%$ pred & $74 \pm 3$ & $64 \pm 2$ & $89 \pm 2$ & $<0.001$ \\
\hline Age yrs & $65 \pm 2$ & $66 \pm 2$ & $64 \pm 3$ & 0.57 \\
\hline Height $\mathrm{cm}$ & $166 \pm 2$ & $167 \pm 2$ & $164 \pm 3$ & 0.39 \\
\hline Weight $\mathrm{kg}$ & $73 \pm 2$ & $72 \pm 3$ & $74 \pm 4$ & 0.68 \\
\hline $\mathrm{BMI} \mathrm{kg} \cdot \mathrm{m}^{-2}$ & $26.5 \pm 1.1$ & $27.4 \pm 1.2$ & $25.3 \pm 2.3$ & 0.39 \\
\hline FEV $1 \%$ pred & $52 \pm 3$ & $46 \pm 3$ & $60 \pm 4$ & 0.01 \\
\hline FVC $\%$ pred & $79 \pm 4$ & $76 \pm 5$ & $83 \pm 7$ & 0.41 \\
\hline FEV $1 / F V C \%$ pred & $44 \pm 3$ & $41 \pm 3$ & $49 \pm 4$ & 0.12 \\
\hline FRC $\%$ pred & $134 \pm 3$ & $145 \pm 8$ & $118 \pm 9$ & 0.04 \\
\hline TLC $\%$ pred & $110 \pm 4$ & $115 \pm 4$ & $103 \pm 6$ & 0.10 \\
\hline $\mathrm{Pa}_{\mathrm{a}, \mathrm{O}_{2}} \mathrm{mmHg}$ & $74 \pm 2$ & $72 \pm 2$ & $77 \pm 2$ & 0.04 \\
\hline $\mathrm{Pa}_{\mathrm{a}, \mathrm{CO}_{2} \mathrm{mmHg}}$ & $40 \pm 2$ & $41 \pm 1$ & $38 \pm 2$ & 0.16 \\
\hline MRC dyspnoea score & $1.9 \pm 0.3$ & $2.3 \pm 0.3$ & $1.5 \pm 0.3$ & 0.04 \\
\hline Baseline VAS score \% (range) & $31 \pm 4(10-61)$ & $38 \pm 4(10-61)$ & $21 \pm 3(11-44)$ & 0.03 \\
\hline Current smoker $\mathrm{n}$ & 9 & 5 & 4 & 0.92 \\
\hline Pack-yrs & $46 \pm 7$ & $53 \pm 6$ & $37 \pm 3$ & 0.04 \\
\hline
\end{tabular}

Data are presented as mean \pm SEM unless otherwise stated. $p$-Values pertain to differences between subjects with basal inspiratory capacity (IC) higher and lower than $80 \%$ predicted. M: male; F: female; BMI: body mass index; FEV1: forced expiratory volume in one second; FVC: forced expiratory capacity; FRC: functional residual capacity; TLC: total lung capacity; $\mathrm{Pa}, \mathrm{O}_{2}$ : arterial oxygen tension; $\mathrm{Pa}, \mathrm{CO}_{2}$ : arterial carbon dioxide tension; MRC: Medical Research Council; VAS: visual analogue scale (standard version). 
were performed using a constant volume/pressure body plethysmograph (Elite DL; MedGraphics $\AA$, St Paul, MN, USA), while mouth and box flow were measured through a pneumotachograph (Elite DL; MedGraphics ( $)$. Volume was obtained by integrating the flow signal. IC was determined by a slow manoeuvre (slow inspiration until maximum volume after regular tidal breathing), while FRC was determined by asking patients to pant at a frequency of $<1 \mathrm{~Hz}$ against a closed shutter [23]. This manoeuvre was followed by a slow manoeuvre to obtain total lung capacity (TLC) and residual volume. Reference values from the European Community for Steel and Coal [24] were used. For IC, predicted values were calculated as the difference between predicted TLC and predicted FRC. For analysis, the highest FEV1 and the highest FVC were selected from three acceptable expiratory manoeuvres, according to the ATS guidelines [2].

The patients were classified as responders and nonresponders to bronchodilators according to a change in FEV1 of more or less than $10 \%$ of the predicted value, as recommended by the European Respiratory Society (ERS) consensus statement [1]. Changes in perception of dyspnoea were assessed with the visual analogue scale (VAS) method (bipolar transitional version), previously used to determine the effects of salbutamol on dyspnoea in COPD patients at rest $[14,25]$. The VAS used was a $20-\mathrm{cm}$ long horizontal line labelled "very much worse" at the left end and "very much better" at the right end, and "no change" in the middle. Care was taken that the patients understood the scale, i.e. the three possibilities of improvement, no change and worsening of breathlessness. All subjects were instructed to mark the VAS line at any point they felt appropriate. Ratings ( $\triangle$ VAS \%) were expressed as the percentage of the distance between zero and $+100 \%$ (very much better), and zero and $-100 \%$ (very much worse). Patients were instructed to rate only breathlessness, ignoring other sensations such as cough and chest tightness. The standard VAS was used to assess the baseline dyspnoea before bronchodilator administration (range $0-100 \%$ ).

\section{Statistical analysis}

Data are presented as mean \pm SEM. Data analysis was carried out on the whole group of patients, and in subjects stratified with and without basal IC reduction ( $80 \%$ pred as cut-off point). Analysis of variance was used for repeated measures and t-test with Bonferroni correction for multiple comparison. The $\Delta \mathrm{VAS}$ scores were analysed both before and after correction for placebo score. The corrected values represented the iso-time difference between $\triangle$ VAS $(\%)$ after drug administration and $\triangle$ VAS $(\%)$ after placebo inhalation. The $\triangle \mathrm{VAS}(\%)$ dyspnoea scores were tested nonparametrically (Friedman test) to minimise assumptions about distribution of data. Correlations were established using the least squares method. As the correlation coefficient (r) increases towards unity, error constitutes a smaller portion of the observed value: $r<0.4$ indicates poor reliability, $r$ of $0.4-0.75$ fair to good reliability, and $r>0.75$ excellent reliability [26]. This analysis was carried out using the $\triangle$ VAS scores as dependent variables; the possible independent variables included FEV1, IC, FVC and FEV1/ FVC. The effect of different drugs on giving significant bronchodilation in terms of changes in FEV1, IC, FVC and FEV1/FVC was compared by means of the Chi-squared test for categorical variables with Yates' correction. A p-value of $<0.05$ was considered significant.

\section{Results}

Table 1 shows the anthropometric and lung function characteristics of the patients (all patients stratified into two groups: with or without a baseline reduction in IC with cut-off at $80 \%$ pred). The 12 patients with baseline IC reduction showed a greater exposure to smoke (pack-yrs) and disease severity (lower arterial oxygen tension $\left(\mathrm{Pa}_{\mathrm{a}} \mathrm{O}_{2}\right)$ and FEV1 and higher FRC; $\mathrm{p}<0.05)$. Moreover, patients with basal IC reduction reported a greater chronic MRC dyspnoea score $(\mathrm{p}=0.04)$ and baseline VAS score $(\mathrm{p}=0.03)$. According to ERS criteria $(\triangle \mathrm{FEV} 1>10 \%$ pred with salbutamol), only six patients were responders.

The changes in FEV1 \% pred, IC \% pred and $\triangle \mathrm{VAS}$ score $(\%)$ after bronchodilator and placebo administration are depicted in figures 1,2 and 3. There was no significant difference in baseline FEV1 and IC in the 5 different study days. Overall, while placebo had no effect on FEV1 and IC, all bronchodilators used caused significant increases in the variables within 5 min of administration, except for salmeterol and oxitropium, which caused a significant increase of IC, 15 and 30 min after drug administration, respectively (figs. 1 and 2). After $30 \mathrm{~min}$, all bronchodilators reached a maximum increase in FEV1 and IC (with no further significant improvement by 60 and $120 \mathrm{~min}$ ), as shown in figures 1 and 2 . In terms of FEV1, 5 and $15 \mathrm{~min}$ after inhalation, formoterol showed a greater improvement than salmeterol and oxitropium but not salbutamol. After 30, 60 and $120 \mathrm{~min}$, all $\beta_{2}$-agonists led to changes in FEV1 significantly greater than oxitropium; formoterol was more effective than salmeterol at $30 \mathrm{~min}(\mathrm{p}=0.01)$. In terms of IC, the overall patient analysis showed that formoterol elicited changes significantly higher than oxitropium, both 15 and $30 \mathrm{~min}$ after bronchodilator inhalation, and higher than salmeterol after $30 \mathrm{~min}$.

Tables 2 and 3 show the changes in IC and FEV1 (expressed as L, \% pred and \% control) after $30 \mathrm{~min}$ in all patients and two subgroups (patients with and without a basal IC reduction). There was essentially no difference if data were expressed in absolute terms (L) or as $\%$ pred or $\%$ control. While there was little or no difference in FEV1 response between the two subgroups of patients, the increase in IC was greater with all bronchodilators in the patients with reduced baseline IC. However, the difference was only significant for formoterol. In patients with reduced 

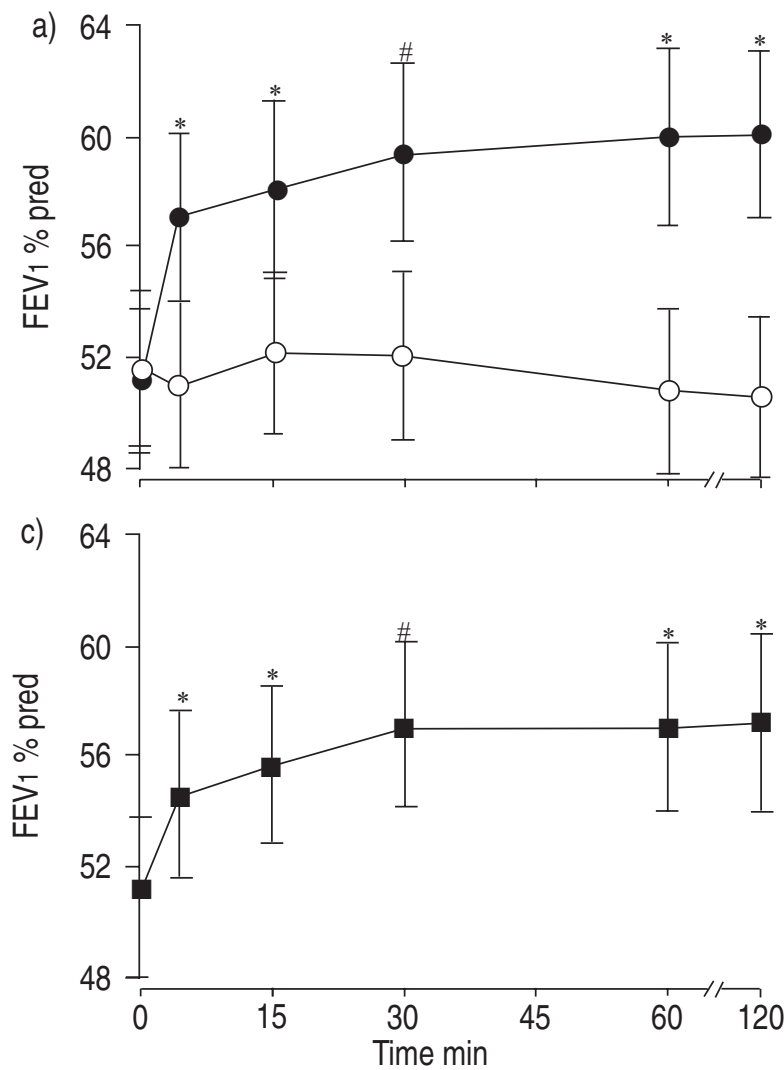

b)

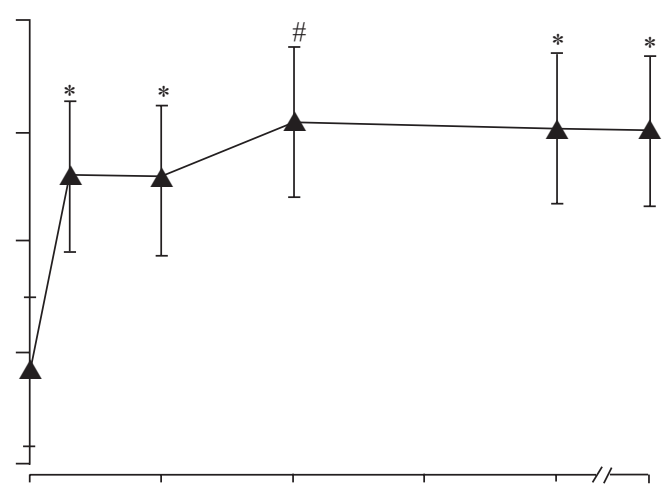

d)

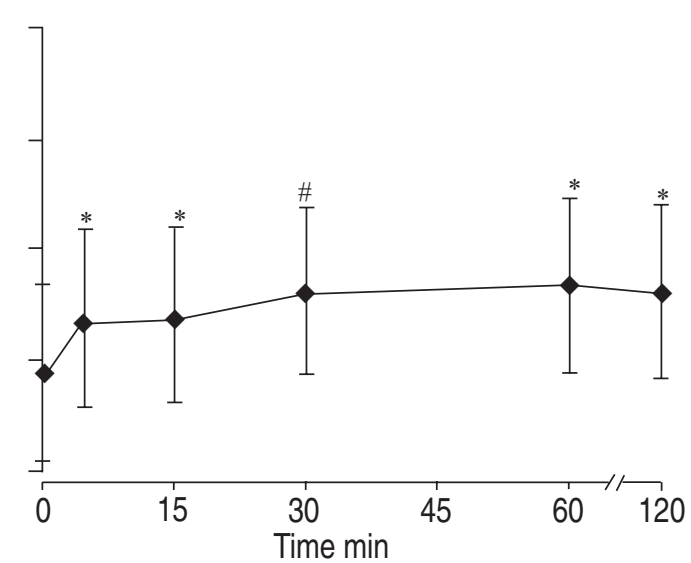

Fig. 1. - Mean \pm SEM change in forced expiratory volume in one second (FEV1) \% predicted after administration of a) salbutamol ( $)$ and placebo $(\bigcirc)$, b) formoterol $(\boldsymbol{\Delta})$, c) salmeterol $(\boldsymbol{\square})$ and d) oxitropium $(\bullet)$. *: p<0.05 compared with baseline. \#: time at which plateau was reached, i.e. no further significant change.

baseline IC, formoterol also elicited a more marked increase in IC than the other bronchodilators. In fact, the difference with both salmeterol and oxitropium was significant $(p<0.05)$. This was not the case in terms of FEV1 response. By $30 \mathrm{~min}$ after drug administration, a plateau response was reached for $\triangle F V C$ and maintained for another $90 \mathrm{~min}$. Table 4 shows the changes in FVC $30 \mathrm{~min}$ after bronchodilator administration. Salbutamol, formoterol and salmeterol elicited $\triangle F V C$ values significantly higher $(\mathrm{p}<0.05)$ than oxitropium in all patient analysis and in both subgroups. There was little or no difference in FVC response between the two subgroups of patients. The FEV1/FVC ratio was not significantly changed after either placebo or any bronchodilator used.

After $30 \mathrm{~min}$ of drug administration, 12 patients had a $\triangle F E V 1$ of $>10 \%$ pred with one or more of the bronchodilators used. Half of these patients had a baseline IC of $<80 \%$ pred, while the other $50 \%$ had a baseline IC of $>80 \%$ pred. In contrast, only two of 12 patients who had a $\Delta \mathrm{IC}$ of $>12 \%$ control [19] had a baseline IC of $<80 \%$ pred.

On average, there was no significant difference in baseline (prebronchodilators) VAS score (standard VAS) between the values obtained on the 5 days in which measurements were made. There was, however, some intrasubject variation that was taken into account when assessing the effects of the four different bronchodilators through use of the bipolar transitional VAS [20, 22]. The changes in bipolar transitional VAS score are shown in figure 3; maximal $\triangle$ VAS $(\%)$ score reduction was achieved $60 \mathrm{~min}$ after bronchodilator and placebo intake. In the 5 different study days, there was no significant difference in basal VAS score (standard version) evaluated before bronchodilator administration. All drugs tested induced a dyspnoea improvement significantly higher than placebo. After $30 \mathrm{~min}$ of bronchodilator administration, $\Delta$ VAS $(\%)$ was higher (through not significantly) for salbutamol and formoterol than salmeterol and oxitropium. On average, in the patients with reduced baseline IC, the decrease of dyspnoea was more marked (though not significantly) than in the patients with basal IC within the normal limits.

As shown in figure 4, $30 \mathrm{~min}$ after bronchodilator administration there was a low $(\mathrm{r}=0.52)$ correlation between the improvement in dyspnoea ( $\triangle \mathrm{VAS}$ score with placebo correction) and $\triangle \mathrm{FEV} 1$ only in patients with a basal IC of $<80 \%$ pred. In these patients there was a close correlation $(\mathrm{r}=0.70)$ between the improvement in dyspnoea and $\triangle \mathrm{IC}$ (fig. 5). In contrast, in the patients with basal IC within the normal limits, this correlation, though significant, was poor. After administration of all bronchodilators the changes of FVC and $\mathrm{FEV} 1 / \mathrm{FVC}$ were not correlated significantly to the concurrent changes in $\triangle \mathrm{VAS}$ scores. 

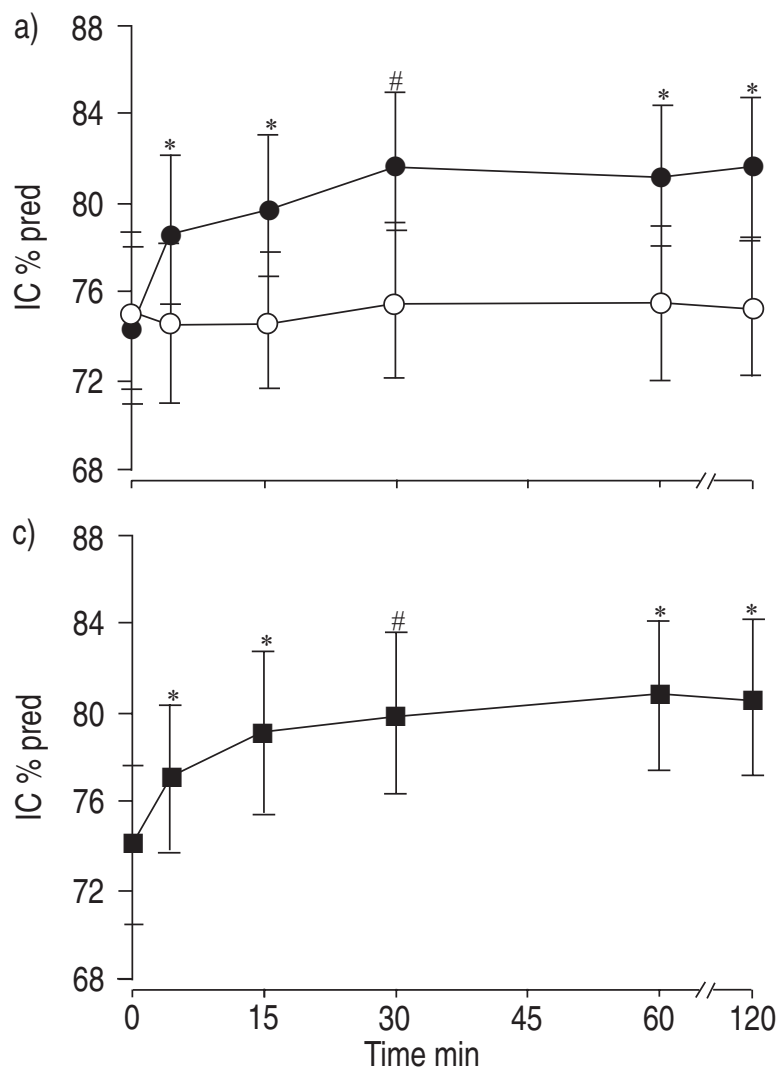

b)

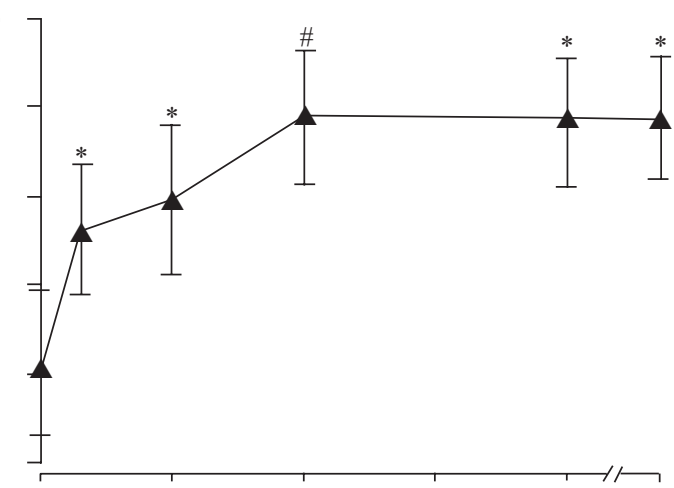

d)

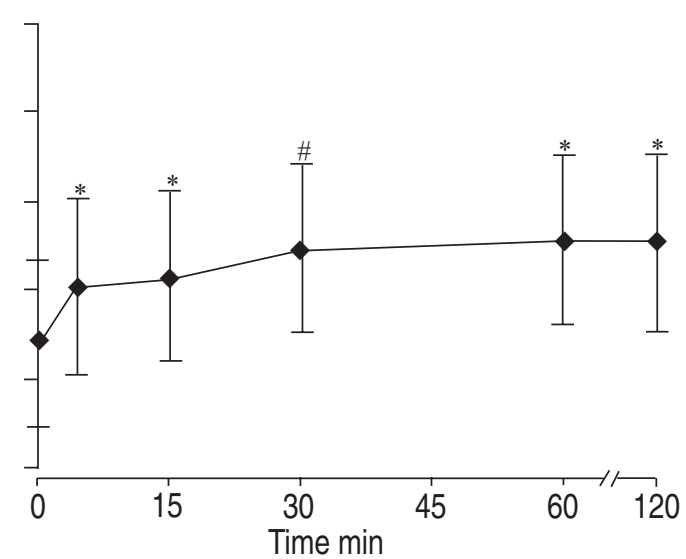

Fig. 2. - Mean \pm SEM change in inspiratory capacity (IC) \% predicted after administration of a) salbutamol ( $)$ and placebo ( $\bigcirc$ ), b) formoterol $(\boldsymbol{\Delta}), \mathrm{c})$ salmeterol $(\boldsymbol{\square})$ and $\mathrm{d}$ ) oxitropium $(\boldsymbol{\bullet})$. $*$ : p $<0.05$ compared with baseline. \#: time at which plateau was reached, i.e. no further significant change.

\section{Discussion}

The main new findings of the present investigation are that in COPD patients with decreased baseline IC there was: 1) a much greater increase of IC after bronchodilator administration, which correlated closely with the improvement of dyspnoea sensation at rest; 2) IC changes reached a plateau $30 \mathrm{~min}$ after drugs inhalation, and thus, for all bronchodilators used, IC reversibility should be tested 30 minutes following administration; and 3) at standard recommended dosage, formoterol elicited the greatest average increase in IC among the four bronchodilators used.

In line with a previous report [3], patients with a reduced baseline $\mathrm{IC}$ had a significantly lower $\mathrm{Pa}_{\mathrm{a}} \mathrm{O}_{2}$ and higher FRC than patients with baseline IC within the normal limits $(\mathrm{p}=0.04)$. Moreover, these patients also had a higher MRC dyspnoea score $(p=0.04)$ and a higher baseline VAS score $(\mathrm{p}=0.03)$ (table 1).

TANTUCCI et al. [19] assessed the effect of salbutamol on IC and FRC in COPD patients stratified into two groups, namely with and without tidal expiratory flow limitation (EFL) measured using the negative expiratory pressure method. They reasoned that DH was more likely to be present in patients with tidal EFL, who should accordingly exhibit a greater improvement of DH after bronchodilator administration than patients without EFL. In line with this prediction, they found that EFL patients exhibited a significant increase in IC and decrease in FRC $(p<0.01)$, while this was not the case in the non-EFL patients. In the present study, the authors stratified the patients according to reduced or normal IC, based on the observation that in patients with tidal EFL, the IC is usually reduced below $80 \%$ pred [3]. There are, however, some problems inherent in both of the above methods of patient stratification.

Although tidal EFL is the most common cause of DH in COPD patients, its presence does not predict the actual degree of hyperinflation. Indeed, if the available expiratory flows are sufficient to sustain resting ventilation, there is no need for the endexpiratory lung volume to increase even if tidal EFL is present [3]. Furthermore, prediction of the normal values of IC is a problem in elderly individuals; the predicted normal values of IC are presently obtained as difference between predicted TLC and predicted FRC. Nevertheless, in view of the fact that measurement of IC is simple and reliable, it should represent a useful marker as to when important changes in lung volume, associated with improvements in resting breathlessness, are likely to occur after bronchodilation administration [27]. The improvement of IC after bronchodilator administration has been shown to predict the improvement of exertional dyspnoea and exercise tolerance in COPD patients $[8,10]$. Recently, in a large population of COPD patients, NEWTON et al. 

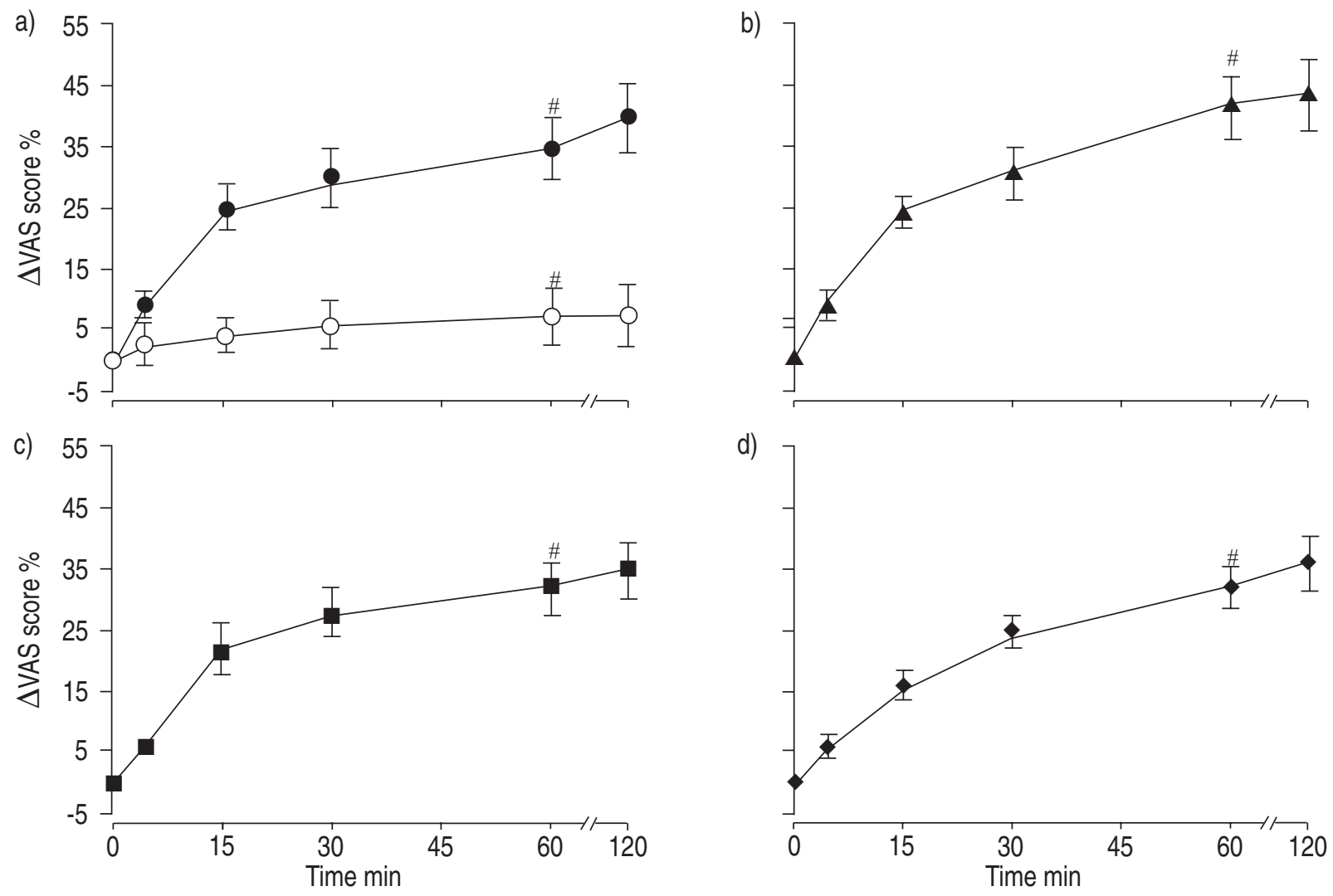

Fig. 3. - Mean \pm SEM change in visual analogue scale (VAS) \% after administration of a) salbutamol (O) and placebo ( $\bigcirc$ ), b) formoterol $(\boldsymbol{\Delta})$, c) salmeterol $(\boldsymbol{\square})$ and d) oxitropium $(\bullet)$. \#. time at which plateau was reached, i.e. no further significant change.

[17] found that the increase of IC after salbutamol administration $(200 \mu \mathrm{g})$ was more pronounced in subjects with more severe hyperinflation. Surprisingly, however, they used TLC as a marker of hyperinflation rather than, more appropriately, FRC or IC.

The above studies, together with other reports $[8$, $12,15-18]$, have clearly shown that standard measurement of $\triangle \mathrm{FEV} 1$ after bronchodilator administration does not uncover significant volume responses that may be more relevant in terms of bronchodilator therapy of COPD patients.
In the present study, it was found that the increase of IC after bronchodilator administration correlated more closely with the improvement of dyspnoea sensation in patients with reduced baseline IC $(\mathrm{r}=0.70)$ than in subjects with baseline IC within normal limits $(r=0.38$; fig. 5). In fact, in patients with reduced baseline $\mathrm{IC}$, the bronchodilators elicited a greater increase of IC than in the patients with baseline IC within normal limits. In a study of 61 COPD patients, TAUBE et al. [14] found that the correlation coefficient between $\triangle \mathrm{VAS}(\%)$ and $\triangle \mathrm{IC}$

Table 2. - Increases in forced expiratory volume in one second (FEV 1 ) and inspiratory capacity (IC) 30 min after drug inhalation

\begin{tabular}{lccccc}
\hline & Bronchodilator & All patients & $\begin{array}{c}\text { Patients with basal } \\
\text { IC }<80 \% \text { pred }\end{array}$ & $\begin{array}{c}\text { Patients with basal } \\
\text { IC }>80 \% \text { pred }\end{array}$ & p-value \\
\hline Subjects & & & 12 & 8 & \\
$\Delta$ FEV1 & Salbutamol & $8.2 \pm 1.0(0.20 \pm 0.02)$ & $7.0 \pm 0.8^{\#}(0.18 \pm 0.02)$ & $10.1 \pm 1.3^{\#}(0.24 \pm 0.02)$ & $0.14(0.20)$ \\
& Formoterol & $9.1 \pm 0.9(0.24 \pm 0.03)$ & $8.6 \pm 0.9^{\#}(0.23 \pm 0.02)$ & $9.8 \pm 1.1^{\#}(0.27 \pm 0.04)$ & $0.54(0.56)$ \\
& Salmeterol & $6.2 \pm 0.8(0.17 \pm 0.02)$ & $6.3 \pm 0.9(0.18 \pm 0.02)$ & $6.0 \pm 0.6(0.16 \pm 0.02)$ & $0.83(0.65)$ \\
$\Delta \mathrm{IC}$ & Oxitropium & $2.8 \pm 0.6(0.07 \pm 0.02)$ & $3.2 \pm 0.7(0.09 \pm 0.02)$ & $2.3 \pm 0.5(0.05 \pm 0.01)$ & $0.49(0.29)$ \\
& Salbutamol & $7.4 \pm 2.1(0.22 \pm 0.06)$ & $10.1 \pm 2.1(0.29 \pm 0.06)$ & $3.3 \pm 1.8(0.10 \pm 0.05)$ & $0.10(0.13)$ \\
& Formoterol & $11.0 \pm 1.7(0.33 \pm 0.05)$ & $14.0 \pm 1.8(0.42 \pm 0.06)$ & $6.4 \pm 0.8(0.18 \pm 0.03)$ & $0.02 *(0.03)$ \\
& Salmeterol & $5.9 \pm 1.9(0.17 \pm 0.06)$ & $8.2 \pm 2.2(0.25 \pm 0.07)$ & $2.5 \pm 1(0.06 \pm 0.03)$ & $0.15(0.12)$ \\
& Oxitropium & $4.3 \pm 1.6(0.14 \pm 0.05)$ & $6.2 \pm 1.7(0.20 \pm 0.05)$ & $1.3 \pm 1.3(0.04 \pm 0.04)$ & $0.14(0.13)$ \\
\hline
\end{tabular}

Data are presented as mean \pm SEM $\%$ predicted $(\mathrm{L}) .{ }^{*}: \mathrm{p}<0.05$ relative to patients with basal IC $>80 \%$. ${ }^{*}$ : significant difference of salbutamol and formoterol to oxitropium in both subgroups of patients $(p<0.05)$ \%: formoterol shows values significantly higher $(\mathrm{p}<0.05)$ than salmeterol and oxitropium only in patients with basal IC $<80 \%$ pred. 
Table 3.-Increases in forced expiratory volume in one second (FEV 1 ) and inspiratory capacity (IC) 30 min after drug inhalation

\begin{tabular}{lccccc}
\hline & Bronchodilator & All patients & $\begin{array}{c}\text { Patients with basal } \\
\text { IC }<80 \% \text { pred }\end{array}$ & $\begin{array}{c}\text { Patients with basal } \\
\text { IC }>80 \% \text { pred }\end{array}$ & p-value \\
\hline Subjects & & & 12 & 8 & $17.0 \pm 1.9^{\#}$ \\
$\Delta$ FEV1 & Salbutamol & $16.0 \pm 1.8^{\#}$ & $15.2 \pm 1.7^{\#}$ & $17.4 \pm 2.1^{\#}$ & 0.62 \\
& Formoterol & $18.4 \pm 2.1^{\#}$ & $19.0 \pm 2.2^{\#}$ & $10.1 \pm 1.0$ & 0.72 \\
& Salmeterol & $13.3 \pm 2.3$ & $15.4 \pm 2.7$ & $3.8 \pm 0.7$ & 0.26 \\
$\Delta \mathrm{IC}$ & Oxitropium & $6.7 \pm 1.7$ & $8.5 \pm 2.0$ & $4.2 \pm 2.1$ & 0.18 \\
& Salbutamol & $11.4 \pm 3.3$ & $16.1 \pm 4.7$ & $2.5 \pm 0.9$ & 0.07 \\
& Formoterol & $16.5 \pm 3.0^{*}$ & $22.5 \pm 4.1^{*}$ & $2.4 \pm 1.2$ & $0.01^{*}$ \\
& Salmeterol & $9.0 \pm 3.2$ & $13.3 \pm 4.8$ & $1.2 \pm 1.4$ & 0.09 \\
\hline
\end{tabular}

Values are means \pm SEM $\%$ control. *: $\mathrm{p}<0.05$ relative to patients with basal IC $>80 \%$. ${ }^{*}$ : significant difference of salbutamol and formoterol to oxitropium in overall patient analysis and in both subgroups $(\mathrm{p}<0.05)$. In overall patient analysis, formoterol was more effective than salmeterol $(\mathrm{p}<0.05)$. ": formoterol shows values significantly higher $(\mathrm{p}<0.05)$ than salmeterol and oxitropium in overall patient analysis and in patients with basal IC $<80 \%$ predicted, but not in patients with basal IC $>80 \%$ pred.

Table 4. - Changes in forced vital capacity (FVC) 30 min after drug inhalation

\begin{tabular}{lccccc}
\hline & Bronchodilator & All patients & $\begin{array}{c}\text { Patients with basal } \\
\text { IC }<80 \% \text { pred }\end{array}$ & $\begin{array}{c}\text { Patients with basal } \\
\text { IC }>80 \% \text { pred }\end{array}$ & p-value \\
\hline Subjects & & 12 & 8 & \\
$\Delta$ FVC & Salbutamol & $9.1 \pm 0.6^{\#}(0.30 \pm 0.02)$ & $8.7 \pm 0.6^{\#}(0.28 \pm 0.02)$ & $9.8 .0 \pm 0.7^{\#}(0.32 \pm 0.02)$ & $0.42(0.41)$ \\
& Formoterol & $10.3 \pm 0.8^{\#}(0.34 \pm 0.03)$ & $10.2 \pm 0.8^{\#}(0.33 \pm 0.03)$ & $10.5 \pm 1.0^{\#}(0.34 \pm 0.03)$ & $0.85(0.91)$ \\
& Salmeterol & $8.0 \pm 0.7^{\#}(0.26 \pm 0.02)$ & $8.3 \pm 0.8^{\#}(0.27 \pm 0.03)$ & $7.4 \pm 0.5^{\#}(0.25 \pm 0.02)$ & $0.51(0.65)$ \\
& Oxitropium & $4.1 \pm 0.8(0.13 \pm 0.03)$ & $4.9 \pm 0.8(0.16 \pm 0.03)$ & $2.8 \pm 0.5(0.09 \pm 0.02)$ & $0.19(0.22)$ \\
\hline
\end{tabular}

Data are presented as mean \pm SEM \% predicted (L); ${ }^{*}$ : salbutamol, formoterol and salmeterol show values significantly higher $(p<0.05)$ than oxitropium in overall patient analysis and in both subgroups. p-Value relative to patients with basal IC $>80 \%$.

(\% control) was low $(\mathrm{r}=0.25, \mathrm{p}<0.05)$. However, they did not stratify their patients according to severity of baseline DH. In fact, the result of the present study shows that such stratification is fundamental because only patients with reduced baseline IC exhibited a good correlation between changes in dyspnoea and $\Delta \mathrm{IC}$ (fig. 5).

The changes in dyspnoea after bronchodilator use also correlated significantly with $\triangle \mathrm{FEV} 1$ in the patients with reduced baseline IC (fig. 4), but the correlation coefficient was lower than that with $\Delta \mathrm{IC}$ (0.52 versus 0.70$)$. No significant correlation was found in the changes in dyspnoea to $\triangle \mathrm{FVC}$ and $\Delta(\mathrm{FEV} 1 / \mathrm{FVC})$.

In the present study, the authors assessed the effect of bronchodilators only on dyspnoea at rest. In a recent study, Boni et al.[8] showed that in COPD patients during exercise $33 \%$ of the maximal predicted workload) the changes in dyspnoea (conventional Borg scale) and $\triangle \mathrm{IC}$ (\% pred) are significantly correlated $(r=0.69 ; p<0.05)$.

In line with previous reports $[8,9,13,14]$, it is likely that the improvement of dyspnoea sensation after bronchodilator administration in COPD is due to reduced $\mathrm{DH}$ with a concurrent decrease in the inspiratory threshold loading (reduced intrinsic positive end-expiratory pressure and inspiratory flow resistance), and improved mechanical advantage of the inspiratory muscles. Hatipoglu et al. [27] tested the hypothesis that in COPD patients the decrease in dyspnoea after salbutamol inhalation might be due in part to increased diaphragmatic contractility, but concluded that the reduction of dyspnoea occurred more as a result of improvement of the length/tension relationship of the diaphragm rather than increased contractility per se.

The present results indicate that, on average, formoterol induced the greatest increase of IC among the four bronchodilators studied, though at $30 \mathrm{~min}$ the difference was significant $(\mathrm{p}<0.05)$ only with salmeterol and oxitropium. It should be stressed that these experiments were limited to 120 min after bronchodilator administration, and in previous studies in COPD patients, it was found that early bronchodilator reversibility in terms of $\triangle \mathrm{FEV} 1$ does not always predict long-term response [28, 29]. AYERS et al. [13] investigated the effectiveness of salmeterol and ipratropium bromide on exertional dyspnoea and IC at 1 and $6 \mathrm{~h}$ after drug inhalation, and found that at $1 \mathrm{~h}$ the changes in IC were similar with salmeterol and ipratropium bromide, while after $6 \mathrm{~h}, \Delta \mathrm{IC}$ was significantly higher with salmeterol than ipratropium $(+19$ and $+9 \%$ of control, respectively). In the present study, salmeterol elicited the highest increase in IC at $1 \mathrm{~h}(10 \%$ of control).

In the present study, all four bronchodilators elicited a significant increase of FEV1 after 5 min of administration and a peak response was achieved by 

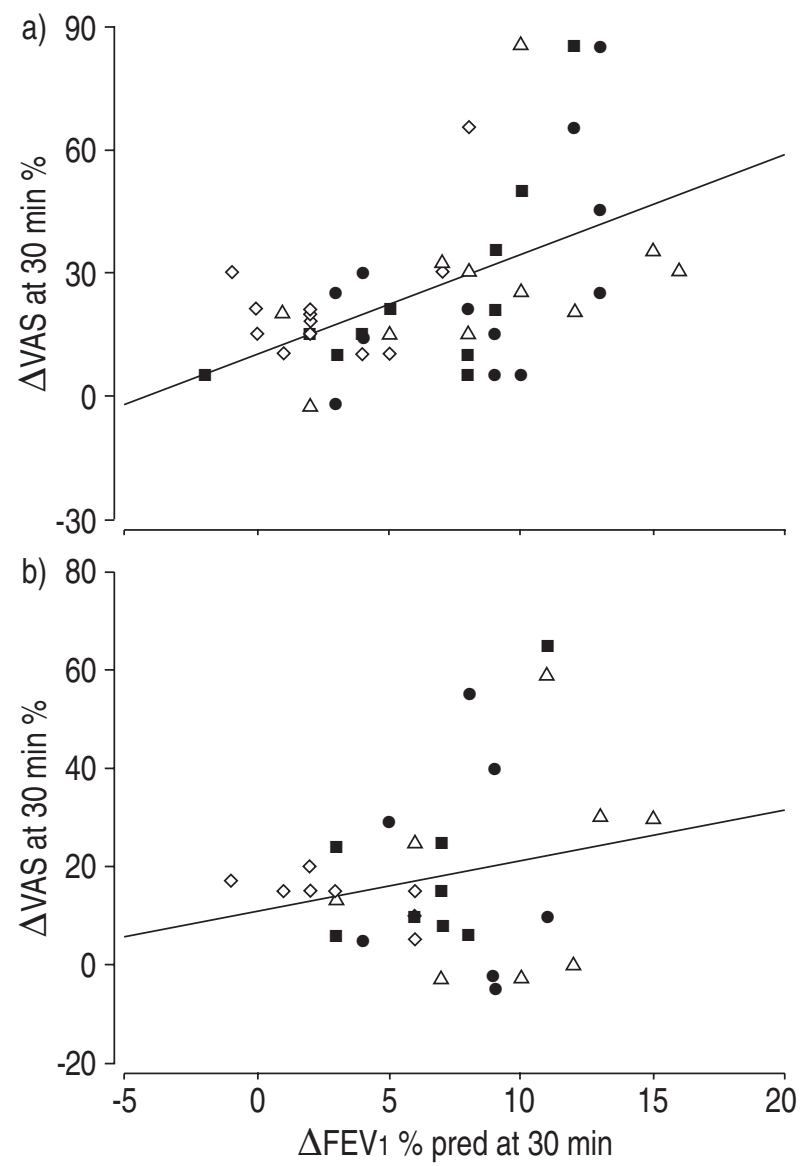

Fig. 4.-Relationship of changes in visual analogue scale (VAS) with placebo correction (\%) with changes in forced expiratory volume in one second (FEV 1$) 30 \mathrm{~min}$ after bronchodilation in patients with baseline inspiratory capacity a) lower $(\mathrm{r}=0.52$; $\left.\mathrm{r}^{2}=0.27 ; \mathrm{p}<0.001\right)$, and b) higher $\left(\mathrm{r}=0.21 ; \mathrm{r}^{2}=0.05 ; \mathrm{p}=0.26\right)$ than $80 \%$ predicted. 0 : salbutamol; $\triangle$ : formoterol; $\mathbf{\square}$ : salmeterol; $\diamond$ : oxitropium.

$30 \mathrm{~min}$ (fig. 1). In contrast, salbutamol and formoterol elicited a significant increase of IC 5 min after administration, while salmeterol and oxitropium showed a significant IC increase only after 15 and $30 \mathrm{~min}$, respectively. In terms of FEV1, a faster onset of action has been reported for salbutamol and formoterol than salmeterol and oxitropium in COPD patients [30]. In line with previous results [17], these data show that there is a dichotomy in the time course of changes in FEV1 and IC after bronchodilator administration. It should also be noted that the plateau increase of $\triangle$ VAS was reached 60 min after bronchodilator administration compared with $30 \mathrm{~min}$ for $\triangle \mathrm{IC}$ and $\triangle \mathrm{FEV} 1$. This probably reflects a central adaptation to respiratory unloading due to reduced $\mathrm{DH}$.

In conclusion, the present results indicate that in chronic obstructive pulmonary disease patients with decreased baseline IC there was a greater increase of inspiratory capacity (reduced dynamic hyperinflation) after bronchodilator administration than in patients with inspiratory capacity within normal limits, which closely correlated with the improvement in dyspnoea sensation at rest. In contrast, the response in terms of
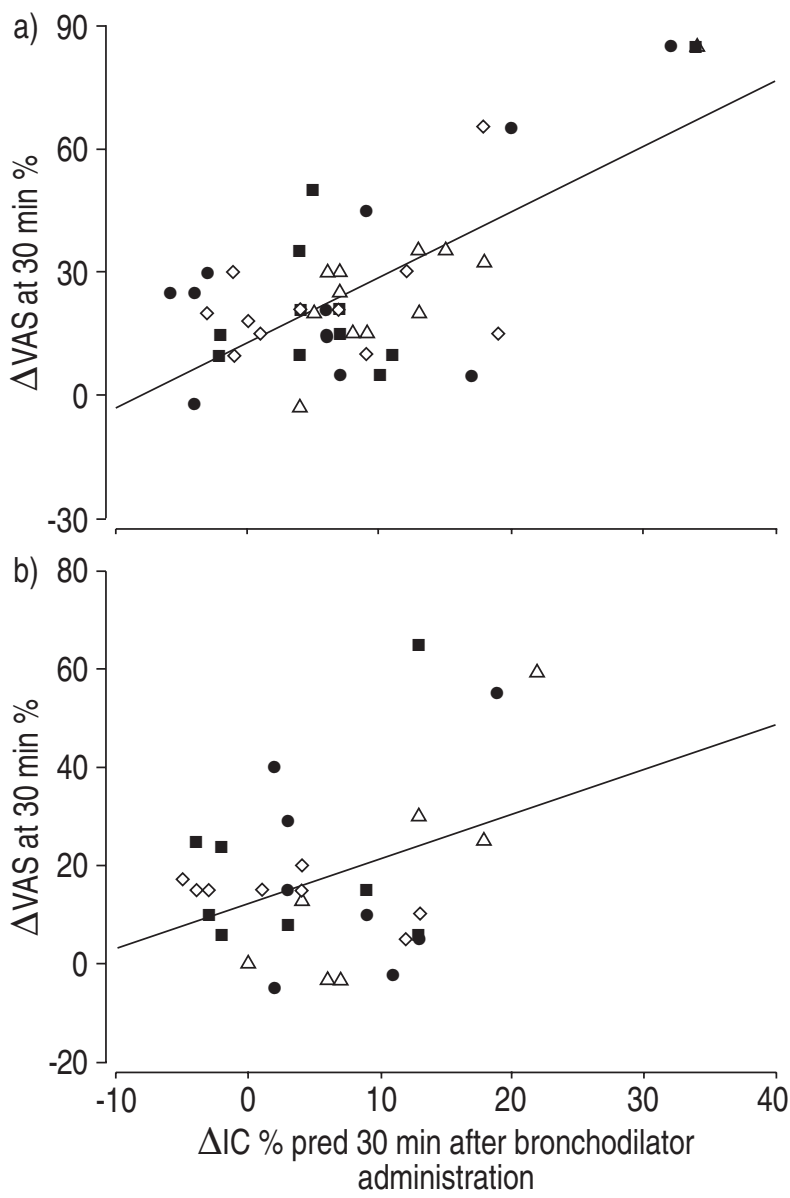

Fig. 5.-Relationship of changes in visual analogue scale (VAS) with placebo correction (\%) with changes in inspiratory capacity (IC) $30 \mathrm{~min}$ after bronchodilation in patients with baseline IC a) lower $\left(r=0.70 ; r^{2}=0.48 ; p<0.001\right)$, and $\left.b\right)$ higher $\left(r=0.38 ; r^{2}=0.15\right.$; $\mathrm{p}<0.05)$ than $80 \%$ predicted. $\bigcirc$ : salbutamol; $\triangle$ : formoterol; $\mathbf{\square}$ : salmeterol; $\diamond$ : oxitropium.

change in forced expiratory volume in one second and forced vital capacity was similar between the two groups of patients. Although the initial rate of change of inspiratory capacity was faster with salbutamol and formoterol than salmeterol and oxitropium, $30 \mathrm{~min}$ after drug administration a plateau response was achieved with all four drugs tested and was maintained for another $90 \mathrm{~min}$; inspiratory capacity reversibility for all bronchodilators used should be tested $30 \mathrm{~min}$ following the drug. At standard recommended dosage, formoterol elicited a greater average increase in inspiratory capacity than the other bronchodilators used, although the difference was only significant with salmeterol and oxitropium. The potential advantage of formoterol over the other drugs tested needs to be further evaluated in a larger patient population.

\section{References}

1. Siafakas NM, Vermeire P, Pride NB, et al. Optimal assessment and management of chronic obstructive 
pulmonary disease (COPD). Eur Respir J 1995; 8: 1398-1440.

2. American Thoracic Society. Lung function testing: selection of reference values and interpretative strategies. Am Rev Respir Dis 1991; 144: 1202-1218.

3. Diaz O, Villafranca C, Ghezzo $\mathrm{H}$, et al. Role of inspiratory capacity on exercise tolerance in COPD patients with and without tidal expiratory flow limitation at rest. Eur Respir J 2000; 16: 269-275.

4. Eltayara L, Becklake MR, Volta CA, Milic-Emili J. Relationship between chronic dyspnoea and expiratory flow-limitation in patients with chronic obstructive pulmonary disease. Am J Respir Crit Care Med 1996; 154: 1726-1734.

5. Hay JG, Stone P, Carter J, et al. Bronchodilator reversibility, exercise performance and breathlessness in stable chronic obstructive pulmonary disease. Eur Respir J 1992; 5: 659-664.

6. Yan S, Kaminski D, Sliwinski P. Reliability of inspiratory capacity for estimating end expiratory lung volume changes during exercise in patients with chronic obstructive pulmonary disease. Am J Respir Crit Care Med 1997; 156: 55-59.

7. Murariu C, Ghezzo H, Milic-Emili J, Gautier H. Exercise limitation in obstructive lung disease. Chest 1998; 114: 965-968.

8. Boni E, Corda L, Franchini D, et al. Volume effect and exertional dyspnoea after bronchodilator in COPD patients with and without expiratory flow limitation at rest. Thorax 2002; 57: 528-532.

9. Marin JM, Carrizo SJ, Gascon M, Sanchez A, Gallego B, Celli BR. Inspiratory capacity, dynamic hyperinflation, breathlessness, and exercise performance during the 6-minute-walk test in chronic obstructive pulmonary disease. Am J Respir Crit Care Med 2001; 163: 1395-1399.

10. O'Donnell DE, Lam M, Webb KA. Spirometric correlates of improvement in exercise performance after anticholinergic therapy in chronic obstructive pulmonary disease. Am J Respir Crit Care Med 1999; 160: 542-549.

11. Pellegrino R, Rodarte JR, Brusasco V. Assessing the reversibility of airway obstruction. Chest 1998; 114: 1607-1612.

12. Pellegrino R, Brusasco V. Lung hyperinflation and flow limitation in chronic airway obstruction. Eur Respir J 1997; 10: 543-549.

13. Ayers ML, Mejia R, Ward J, Lentine T, Mahler DA. Effectiveness of salmeterol versus ipratropium bromide on exertional dyspnoea in COPD. Eur Respir $J$ 2001; 17: 1132-1137.

14. Taube C, Lehnigk B, Paasch K, Kirsten DK, Jorres RA, Magnussen H. Factor analysis of changes in dyspnoea and lung function parameters after brochodilation in chronic obstructive pulmonary disease. Am J Respir Crit Care Med 2000; 162: 216-220.

15. Belman MJ, Botnick WC, Shin JW. Inhaled bronchodilators reduce dynamic hyperinflation during exercise in patients with chronic obstructive pulmonary disease. Am J Respir Crit Care Med 1996; 153: $967-$ 975.

16. Hadcroft J, Calverley PMA. Alternative methods for assessing bronchodilator reversibility in chronic obstructive pulmonary disease. Thorax 2001; 56: 713-720.
17. Newton MF, O'Donnell DE, Forkert L. Response of lung volumes to inhaled salbutamol in a large population of patients with severe hyperinflation. Chest 2002; 121: 1042-1050.

18. O'Donnell DE, Forkert L, Webb KA. Evaluation of bronchodilator responses in patients with "irreversible" emphysema. Eur Respir J 2001; 18: 914-920.

19. Tantucci C, Duguet A, Similowski T, Zelter M, Derenne J-P, Milic-Emili J. Effect of salbutamol on dynamic hyperinflation in chronic obstructive pulmonary disease patients. Eur Respir J 1998; 12: 799-804.

20. Pauwels RA, Buist AS, Calvereley PMA, Jenkins CR, Hurd SS. Global strategy for the diagnosis, management, and prevention of chronic obstructive pulmonary disease. NHLBI/WHO Global Initiative for chronic obstructive lung disease (GOLD) workshop summary. Am J Respir Crit Care Med 2001; 163: $1256-1276$

21. American Thoracic Society. Standards for the diagnosis and care of patients with chronic obstructive pulmonary disease. Am J Respir Crit Care Med 1995; 152: S77-S120.

22. Speizer F, Comstock G. Recommended respiratory diesease questionnaires for use with adults and children in epidemiological research. Epidemiology Standardization Project. Am Rev Respir Crit Care Med 1978; 118: 7-53.

23. Shore SA, Huk O, Mannix S, Martin JG. Effect of panting frequency on the plethysmographic determination of thoracic gas volume in chronic obstructive pulmonary disease. Am Rev Respir Dis 1983; 128: 54 59.

24. Quanjer $\mathrm{PhH}$, Tammelin GJ, Cotes JE, Pedersen OF, Peslin R, Yernault J-C. Lung volumes and forced ventilatory flows. Report Working Party "Standardization of Lung Function Tests". European Coal and Steel Community. Eur Respir J 1993; 6: Suppl. 16, 5s40s.

25. Noseda A, Schmerber J, Prigogine T, Yernault JC. How do patients with either asthma or COPD perceive acute bronchodilation? Eur Respir J 1993; 6: 636-644.

26. Fleiss JL. Reliability of measurement. In: Fleiss JL, ed. The Design and Analysis of Clinical Experiments. New York, John Wiley \& Sons, 1986; pp. 1-45.

27. Hatipoglu US, Laghi F, Tobin MJ. Does inhaled albuterol improve diaphragmatic contractility in patients with chronic obstructive pulmonary disease? Am J Respir Crit Care Med 1999; 160: 1916-1921.

28. Cazzola M, Vinciguerra A, Di Perna F, Matera MG. Early reversibility to salbutamol does not always predict bronchodilation after salmeterol in stable chronic obstructive pulmonary disease. Respir Med 1998; 92: 1012-1016.

29. Rennard SI, Anderson W, ZuWallack R, et al. Use of a long-acting inhaled beta $_{2}$-adrenergic agonist, salmeterol xinafoate, in patients with chronic obstructive pulmonary disease. Am J Respir Crit Care Med 2001; 163: 1087-1092.

30. Celik G, Kayacan O, Beder S, Durmaz G. Formoterol and salmeterol in partially reversible chronic obstructive pulmonary disease: a crossover, placebo controlled comparison of onset and duration of action. Respiration 1999; 66: 434439. 